\title{
Construindo novas histórias do conhecimento: um estudo iconográfico do ensino na universidade medieval
}

\author{
Iconographic study for the integration of a history of knowledge
}

Giulia Crippa

Doutora em História Social pela Universidade de São Paulo - USP

Professora do curso de Ciências da Informação e Documentação da FFCLRP/USP

E-mail: giuliac@ffclrp.usp.br

\begin{abstract}
Resumo
Esse trabalho pretende abordar um conjunto de imagens, encontradas principalmente em monumentos funerários localizados em Bolonha (Itália), no Museu Medieval da cidade e em algumas igrejas do território nacional que se caracterizam, a partir dos primeiros anos do século XIV, por apresentar o tema do ensino universitário através de cenas em que se destaca o "Mestre", empenhado em lecionar aos seus estudantes. Peculiaridade dessas imagens é que elevam ao espaço monumental da memória religiosa - o cemitério - uma figura recém aparecida no espaço urbano, inserida em uma profissão cuja finalidade era o pecus, o lucro, e a fama: o Mestre Laico. O artigo esboça a trajetória histórica da institucionalização do conhecimento dos chamados "filósofos", visto com suspeita pelos elementos eclesiásticos, até então principais protagonistas da arquitetura do conhecimento medieval. A figura que representa a posição social e profissional dos mestres laicos, assim realizada é, porém, o resultado da busca de espaços legítimos de reconhecimento intelectual no âmbito da universidade, através de conflitos que amadurecem e se revelam ao longo do século XIII, quando a expansão dos currículos, proposta já na metade dos século XII por personalidades como Hugo de São Vítor, leva a uma ampliação da base docente ativamente empenhada nas faculdades de medicina, de direito e, em grande medida, nas artes liberais e mecânicas.
\end{abstract}

Palavras Chave: Universidade; Conhecimento; Iconografia; Cultura Medieval

\begin{abstract}
This paper pretend to discuss a group of images that illustrate the subject of university, through scenes in which the main character is the Master in his duty of teaching students. These scenes are mainly found in funerary monuments from the beginning of the XIVth century, located mainly in Bologna (Italy) at the Medieval Museum of the city and in some churches on the national territory. They bring to the monumentary space of religious memory - the cemetery - a new social actor, recently appeared in urban space, dedicated to a profession which aim was the pecus, the gain, and the fame: the Laic Master. The paper draws the historical trajectory of the institutionalization of knowledge of the so called "philosopher", suspiciously saw by the ecclesiastic elements, who, until then, were the main characters of the arquitecture of medieval knowledge. The images produced by the monuments, representing the social and professional position of the Laic Masters, is, nonetheless, the results of the search for legitimate spaces of intellectual reward in university, through conflicts that develop and manifest through the XIIIth century. This is when the modification of the curricula, already proposed since the middle XIIth century by personalities such as Hugo of Saint Victor, results in a larger base of teachers, actively engaged in faculties such as medicine, law and, in a great deal, such as liberal and mechanical arts.
\end{abstract}

Key-words: University; Knowledge; Iconography; Medieval Culture.

InCID: R. Ci. Inf. e Doc., Ribeirão Preto, v. 1, n. 2, p. 60-76, jul./dez. 2010. 


\section{Introdução}

A partir do séc. XIV assiste-se ao aparecimento e proliferação de elementos iconográficos que remetem à vivência intelectual de âmbito universitário. O repertório, vasto, remete com freqüência ao ofício do ensino, e comporta o aparecimento de uma figura inédita na iconografia: a do Mestre Laico, professor que não pertence às fileiras das ordens religiosas. Tanto as evidências iconográficas como as fontes escritas concorrem para a codificação de um ideário sobre os intelectuais não religiosos da época, fornecendo temas e sugestões para uma investigação sobre seus papeis e relações de autoridade na construção do espaço universitário. A busca de uma afirmação como categoria ligada a uma instituição de grande resistência no tempo pode ser individualizada na constituição de elementos iconográficos que tendem à promoção de uma categoria específica, qualificada em termos de equipamentos culturais para identificar e instituir categorias intelectuais de maneira autônoma dentro de um espaço de matriz religiosa.

Indicador da crescente valorização de uma profissão urbana, a iconografia dos Mestres Laicos favorece uma abordagem histórica diferenciada: o estudo de séries monumentais permite, de fato, observar a qualificação crescente desse grupo social destinado a adquirir espessura intelectual e a definir seu papel como grupo de poder específico e, ao mesmo tempo, em diálogo constante com outros poderes presentes no território urbano.

A riqueza do tema não permite seu esgotamento nesse trabalho, que visa, principalmente, estabelecer alguns pontos de partida para uma discussão mais ampla e, para isso, tentaremos esboçar a trajetória histórica de um conhecimento, o dos chamados "filósofos", visto com suspeita pelos elementos eclesiásticos, até então principais protagonistas da arquitetura do conhecimento medieval.

Esse trabalho pretende abordar um conjunto de imagens, encontradas principalmente em monumentos funerários, que se caracterizam, a partir dos primeiros anos do século XIV, por apresentar o tema do ensino universitário através de cenas em que se destaca o "Mestre", empenhado em lecionar aos seus estudantes. Peculiaridade dessas imagens é que elevam ao espaço monumental da memória religiosa - o cemitério - uma figura recém aparecida no espaço urbano, inserida em uma profissão cuja finalidade era o pecus, o lucro, e a fama: o Mestre Laico.

InCID: R. Ci. Inf. e Doc., Ribeirão Preto, v. 1, n. 2, p. 60-76, jul./dez. 2010. 
É conhecido como Magister Naturalis Scientiae ou Logicalis Scientiae (DE LIBERA, 1999, p. 11) e, com bastante frequiência, as duas qualificações se encarnam em uma única figura. Em Bolonha é chamado de doctor ou até de dominus (VERGER, 2001, p. 153) especialmente quando se trata de um jurista da Faculdade de Direito, indício, esse, que aponta para a qualificação de um status que se revela, concretamente, na autonomia dessa universidade em relação à comuna e ao imperador. Entende-se, aqui, o termo "laico" em seu sentido mais restrito, ou seja: que não pertence às fileiras de alguma ordem religiosa. Esse termo não abrange o sentido moderno de separação entre cível e religioso, pois se trataria de um grave anacronismo.

\section{Questões metodológicas}

Quais são as características dessas imagens, que as tornam objeto de interesse para integrar uma história do conhecimento e de seus atores? De um lado se observa a natureza artística do objeto, suas qualidades formais, a autoria, conhecimentos fornecidos pelo campo da

história da arte. É necessário, todavia, transpor as fronteiras dos campos do conhecimento atuais, para chegarmos ao estudo de fenômenos artísticos como campo de indagação da história cultural. O "engate" teórico capaz de tornar o fato artístico uma fonte para o historiador, que permite a abordagem do campo visual na mesma lógica de tratamento de um arquivo documental, domínio mais propriamente histórico, torna-se possível por:

1) Uma renovação epistemológica que se verifica no campo da história da arte através dos estudos realizados pelos discípulos de Aby Warburg, entre eles Panofsky (1975), Gombrich (2003), Saxl (2005). A mudança de enfoque sobre os fenômenos artísticos se atrela a uma "antropologia da visão", considerada por Warburg a faculdade primeira de apreensão da mente humana. Para ele, nossa mente apreende o mundo através de três faculdades: a visão, a palavra, a orientação e a ação (GOMBRICH, 2003, p. 277-290; SETTIS, 2000, p. 108-150). Essas quatro faculdades mentais, quando organizadas, geram proximidades diferentes na ordem do conhecimento, que desencadeiam caminhos inéditos. O fundamento epistemológico a partir do qual se discute o que é história se encontra definido nas obras de Francis Bacon portanto, em uma discussão Aristotélica. As faculdades baconianas - razão, imaginação e memória - classificam os campos do conhecimento. A arte, produto da razão, não encontra a 
história, expressão da memória, nem a literatura, produto da imaginação. A História Cultural é fronteira aberta bilíngüe que se institui no encontro entre a discussão da Nova História e a proposta da escola de Warburg.

2) A história cultural, quando se ocupa de iconografia, entende a autonomia da linguagem da arte, buscando, assim, caracterizar as partes dessa linguagem. Dessa forma, é possível identificar modelos iconográficos a serem considerados pelo historiador. O objeto de arte se torne parte de uma série de "documentos iconográficos", que provocam inquietações ao historiador cultural, que busca as razões do aparecimento da iconografia, sua consistência como série, propondo hipóteses sobre suas funções como meio de transmissão de valores socialmente construídos em sua legitimidade.

Consideramos essencial essa pequena premissa de método, para elaborar as hipóteses que norteiam o esboço de um mapa da iconografia do mestre laico:

a) A iconografia encontrada marca um espaço ideológico claro no uso contínuo de referências formais ao espaço religioso, lugar de legitimação por excelência na universidade e, mais em geral, na sociedade medieval.

b) O aparecimento da iconografia dessa categoria social, produto do meio urbano, através de sua principal instituição cultural, a Universidade, é resultado do processo contrastado de sua legitimação social.

c) A fonte iconográfica tende a derrubar as temporalidades históricas que delineiam o campo de estudos medievais: o caso da iconografia universitária legitima saberes oriundos de forças urbanas e laicas que ocupam legitimamente espaços de poder antes reservados aos membros da Igreja.

\section{Construindo séries}

Com essas hipóteses, fomos observar os monumentos funerários produzidos ao longo do século XIV, presentes nas grandes cidades universitárias, com particular atenção aos túmulos dos juristas e médicos que compuseram os quadros do conhecimento bononiensis, hoje conservadas 
no Museu cívico medieval da cidade, mas originariamente locadas no cemitério do convento e da igreja de São Domingos, da ordem franciscana.

É nessa época que, de fato, se torna uma prática difusa nas grandes cidades universitárias, por parte dos docentes, dedicar monumentos funerários a si e à própria ciência. O monumento dedicado a Cino de Pistoia, jurista, visível na catedral de Pistoia, do começo do século XIV, apresenta a tipologia mais emblemática: esculpidas na tampa estão cinco figuras, uma em tamanho muito maior, Cino lecionando, sentado, entre os quatro discípulos, as figuras menores. No friso da base, um baixo-relevo ilustrando uma sala de aula, com o catedrático lecionando para nove estudantes, sentados em suas carteiras. Na margem esquerda, uma figura em pé, de braços cruzados, observando. O espaço dos alunos, aparentemente "naturalizado" pela diferenciação dos gestos, revela o modelo constante das figuras: observem-se, em particular, três delas: o estudante entediado que sustenta o queixo com uma mão na primeira fila, aquele que apóia um dedo aos lábios, em ato de reflexão, no fundo, e aquele empenhado na leitura.

O túmulo de Mateus Gandoni, originariamente colocado no claustro de São Domingo, em Bolonha, e hoje conservado no Museu Cívico Medieval da mesma cidade, é datado de 1330. Este monumento revela a presença do modelo que apóia o queixo na mão, verdadeiro topos não somente iconográfico, mas também literário, assim como permite reconhecer, na figura em pé, presente em ambas as pedras, o bedellus, bedel, a quem cabe, entre as outras tarefas, o controle dos professores, garantido que desempenhem suas aulas.

No sepulcro de dois famosos médicos de Bolonha, Lucio e Mondino de' Liuzzi, estão presentes as figuras do tédio e da leitura ativa, provocando um contraste imediato pela sua proximidade. Os baixo-relevos da arca de João de Legnano, jurista sepultado em 1383, apresentam, novamente, as três figuras, do leitor, do tédio e da reflexão. Dois fragmentos de um sepulcro perdido atribuído ao começo do século XV se concentram, novamente, no contraste entre o tédio e a leitura.

Trata-se de modelos iconográficos que compõem uma síntese do mundo estudantil através do filtro de elementos literários e de iconografias anteriores, não podendo ser interpretados, nesse sentido, como narração e reflexo da realidade quotidiana da sala de aula universitária. Reconhecemos, nesses modelos, determinadas convenções iconográficas que instituem parâmetros de representação comuns do sentir as atividades universitárias.

InCID: R. Ci. Inf. e Doc., Ribeirão Preto, v. 1, n. 2, p. 60-76, jul./dez. 2010. 
Por outro lado, observa-se a construção ideológica que a figura do docente revela em sua exposição. Exemplar é, novamente, a arca de Cino da Pistoia, considerando agora o grupo esculpido na parte superior. Que se trate de uma inspiração direta de modelos religiosos aparece com clareza na perspectiva hierárquica aqui proposta: assim como as imagens sacras caracterizam, pelo tamanho diferenciado, os graus de sacralidade/importância das personagens representadas, no caso desse grupo de esculturas o tamanho diferente da estatua do mestre, mais do dobro que as outras, se impõe com a força de uma imagem tradicional de veneração, com a diferença de que se trata de uma figura terrena, laica, e dedicada ao ensino em uma faculdade diversa da teologia. Trata-se, portanto, de um monumento que consagra um filósofo, e não um teólogo.

A audácia desse recalque, porém, só se revela quando considerada à luz das disputas que envolveram, ao longo da segunda metade do século XIII, teólogos e filósofos. Esse tipo de representação revela uma hierarquização, através das formas, que sustenta um aparato ideológico que legitima o filósofo como portador de qualidades superiores, em certa medida associadas ao espaço sagrado.

Tomemos uma ilustração do Inventaire de Chirurgie, de Guy de Chauliac, contida em um manuscrito de 1468. O texto, em gótico francês, é composto de duas partes, os Segres des dames defendus à reveler, contendo as regras de obstetrícia em vulgar, de autoria desconhecida, e o texto mais famoso de Chauliac (1300-1367), considerado o pai da cirurgia, que cuidou de bem três papas, o próprio Inventaire. A imagem, de alta qualidade, retrata um professor, sentado em cátedra, com um livro nas mãos, cercado pelos santos Cosme e Damião, com uma espátula e um ungüento e, aos pés, quatro discípulos. Aqui, também, a proporção favorece a figura do professor que, sentado, tem a mesma altura dos dois santos e está no mesmo nível, superior, em que eles se encontram. O efeito é reforçado pelo fundo contra o qual a figura do mestre é colocada, um pano azul com estrelas douradas, que coloca idealmente a figura em um espaço próximo da esfera celestes. Por contraste, os discípulos estão em um plano inferior e de tamanho bem menor, obtendo o mesmo efeito ideológico já encontrado no túmulo de Cino de Pistoia.

A figura que representa a posição social e profissional dos mestres laicos, assim realizada é, porém, o resultado da busca de espaços legítimos de reconhecimento intelectual no âmbito da universidade, através de conflitos que amadurecem e se revelam ao longo do século XIII, quando 
a expansão dos currículos, proposta já na metade dos século XII por personalidades como Hugo de São Vítor, leva a uma ampliação da base docente ativamente empenhada nas faculdades de medicina, de direito e, em grande medida, nas artes liberais e mecânicas.

\section{O conhecimento medieval}

Há uma dialética estrutural entre o mundo dos vivos e o dos mortos na Idade Média, e o primeiro somente adquire importância quando confrontado com o segundo. Alguns aspectos relativos ao espaço, ao tempo e à luz se revelam modelos paradigmáticos para observar os vínculos analógicos entre esses dois mundos. À luz das definições desses elementos, o mundo medieval pré-escolástico, substancialmente alheio ao conhecimento da física aristotélica, resolve os problemas "físicos" da alma e dos lugares do além (BASCHET, 2002, p. 317-348). O conhecimento da obra do Estagirita, renovado pela escolástica, consegue solucionar os problemas metafísicos exatamente tornando materiais e físicos os lugares do além. Não se trata somente do surgimento do purgatório, sem dúvida a expressão concreta da melhor geografia medieval, mas da aplicação das leis da física às estruturas dos lugares do além, tornando-as assim compreensíveis aos limites humanos. Se, de um lado, o Inferno é o lugar eterno das almas pecadoras, as ricas imagens das punições que ele fornece desde a visão de São Paulo tornam sua compreensão metafísica desde cedo compreensível à comunidade cristã, pois o conceito de punição do pecado pela dor do fogo e do gelo se torna facilmente compreensível na materialidade cotidiana. Diferente é a concepção do Paraíso, que se torna "material" para a comunidade principalmente através de sua essência luminosa. Essa operação se realiza, com certeza, na poesia dantesca, obra que vulgariza doutrinas, graças à gigantesca operação lingüística do poeta, com certeza, além da extraordinária realização poética. Dante, descrevendo exaustivamente a natureza física dos lugares do além, seus espaços, seus tempos e seus fenômenos luminosos, encerra uma longa jornada de sistematização do mundo dos vivos e dos mortos. A designação dos campos "literatura" e "ciência" definem, a posteriori, a colocação da Divina Commedia no primeiro, levando a leitura a privilegiar os estudos de natureza literária e lingüística.

A grande mediação cultural operada pelo surgimento e organização do espaço

universitário visa fornecer os instrumentos intelectuais que permitam a transformação do 
repertório escrito e documental em ação destinada à propagação de idéias e à realização de um ideal terreno moldado na Jerusalém Celeste de matriz agostiniana. É a partir de um horizonte de crenças que se molda uma organização social ideal que deve se realizar, portanto deve ser conhecida por todos, esclarecendo suas regras, sua conformação e organização.

Entre os séculos XI/XII a formulação teológica da Escolástica adquire seu peso maior, por meio de suas estruturas universitárias, com sua lógica e argumentação escrita (LE GOFF, 1993; PANOFSKY, 1986). É necessário, porém, que a organização “pensada” pelos organismos intelectuais da Igreja alcance as massas iletradas, provocando efeitos eficazes de recepção e interpretação da informação, como o programa narrativo realizado pelas imagens que decoram as igrejas góticas, tradução visual da ortodoxia da Igreja. Para tanto, é necessária uma mediação entre as doutrinas complexas e a comunidade no sentido mais amplo, operação que se realiza no plano da cultura intermediária, capaz de alcançar a massa iletrada. Da mesma forma, o estudo renovado das artes recoloca a centralidade da pregação, expressão verbal do pensamento teológico, que se realiza através do estudo e da aplicação da retórica. Esse conjunto de técnicas do discurso permite a articulação de um pensamento hegemônico dentro da sociedade, realizando uma expressão dos elementos religiosos através de sua exposição imagética que se converte em manutenção do poder e da sociedade existentes. Com efeito, o monopólio do sermão popular é da própria Igreja, que impede a difusão de outras idéias, exatamente pela proibição do exercício da pregação pública aos que não pertencem às suas fileiras. (BOLZONI, 2002; VERGER, 1999)

Sob essa luz, o rigor doutrinário da Divina Commedia, graças ao conjunto poético e lingüístico, é acessível à compreensão dos atores sociais que não participam ativamente de sua elaboração formal e, principalmente, conceitual. Esse rigor, em relação ao canto mais metafísico da obra, o Paraíso, se constrói na sustentação que a física aristotélica oferece à matéria dos astros e na rigorosa aplicação da doutrina da luz, enraizada na concepção agostiniana, mas aqui explicitada pelo modelo de conhecimento escolástico.

A física e a metafísica pertencem ao mesmo campo semântico, como didaticamente explica a seus estudantes Hugo de São Vítor (2001), na medida em que identifica o horizonte hermenêutico do humano na exegese bíblica, realizada nos níveis mundano, alegórico e tropológico, ou seja, ciência, maravilha e salvação. A Commedia realiza o caminho da salvação do homem na História atravessando um mundo metafísico que é causa e princípio das próprias 
leis físicas que regem o cosmos. A essência das leis governa em Deus, e a ordem que se formula no Cosmos, resguardando os princípios dos mistérios da vontade divina. "Vuolsi cosi lá dove si puote ció che si vuole” (ALIGHIERI, 2005, p. 95-96), já declara Virgílio na entrada do Inferno, como explicação plausível do paradoxo da presença corporal de Dante no além, é a ordem metafísica da leis da física. Os três lugares do além "cristalizados" no poema de Dante não somente respeitam, como são causa do mundo físico, tornando-se paradigma, para o mundo dos vivos, do tempo, do espaço e da luz.

A Divina Commedia se torna objeto de comentários e de pregação nas praças e nas igrejas. Além de seu força evocativa dos terrores e das delícias do além, o poema desempenha a tarefa de organizar os saberes da ciência medieval dentro de uma narrativa poética capaz de alcançar um amplo público receptor, ao mesmo tempo, da progressão do pecado e da salvação, também dos elementos que constituem o funcionamento do universo físico, fornecendo um mapa do conhecimento detalhado aos leitores/ouvintes.

A Idade Média se propõe realizar um inventário do saber, baseado em uma lógica neoplatônica e agostiniana, ou seja, nos princípios de "emanação" da divindade. No coração da teoria do conhecimento elaborada pelos pais da Igreja se coloca a teoria das faculdades da alma: potência imaginativa (imaginatio), que registra as impressões dos sentidos e produz imagens mentais; memória, que preserva tais imagens; intelecto (intellectus), que permite julgá-las, separando o verdadeiro do falso, de entender e acessar à fonte de todo o saber, ou seja, Deus. O visível, que pertence aos corpos e aos sentidos é, em princípio, a primeira etapa do conhecimento (SCHMITT, 1989, p. 311-313). O Speculum ou Imago, como produção intelectual, realiza a possibilidade de ver refletida em todas as criaturas a perfeição divina. Nesse sentido deve ser entendida a enciclopédia, como possibilidade de reconstituir a similitudo da origem. Na medida em que a idéia de uma ordem fechada e concluída se sustenta na fé da identidade entre "ordo rerum" e "ordo verborum", primeira tarefa do compilador é revelar a concordância entre ciências e artes, a hierarquia que as harmoniza, e a ordem divina e providencial do Universo (CARNAZZI; FEDRIGA, 2002, p. 106-108).

Trata-se de obras organizadas como coleções de materiais, prescindindo de um critério de síntese. Os Specula se apresentam como sucedâneo da biblioteca, coleções de materiais que se tornam disponíveis para a consulta em um tempo em que a dificuldade de produção do registro 
escrito torna os livros objeto precioso de sua conservação. O problema da época era, de fato, tornar efetiva a disseminação do conteúdo desses preciosos objetos que são os livros manuscritos, mas não o objeto em si.

\section{Textos e contextos para novos Mestres}

O século XII, que institui e institucionaliza o espaço da universidade, revela-se sensível à demanda urbana de ampliação do conhecimento por parte, principalmente, dos profissionais ligados ao sistema de artes e ofícios das profissões urbanas: já no século XII os juristas, os notários, os médicos, os professores aparecem como elementos novos e em busca de um lugar reconhecido. Especialmente em relação à legitimação do tabelião como produtor de documentos fidedignos face seu próprio título, muitos são os estudos existentes, especialmente graças às mais recentes pesquisas de diplomáticos e arquivistas, enquanto em relação às outras categorias a natureza dos estudos existentes não parece enfatizar o aspecto da legitimidade social dos novos protagonistas urbanos. Duas são, no século XII, as tradições cristãs legítimas que estabelecem as categorias do conhecimento humano, ou seja, a base epistemológica do conhecimento que estabelece a classificação dos saberes (VERGER, 2001, p. 65-88). De um lado, a tradição de maior peso descende da tradição platônica que, através dos estóicos, chega a Agostinho e Isidoro; do outro, uma divisão que, fundamentada em Aristóteles, tinha se firmado através de Boécio; essa segunda tradição, todavia, faltava das fontes do filósofo, para se alimentar.

Em ambas, o conhecimento humano era identificado com a filosofia. Para os platônicosagostinianos, a filosofia era constituída pelo conhecimento do mundo físico, ético e lógico. Os aristotélicos-boecianos dividiam a filosofia em conhecimento de natureza teórica, prática e poética.

Quando Hugo de São Vítor propõe sua estrutura do conhecimento, ou seja, os estudos que devem ser realizados nas escolas para se tornar filósofo, por volta de 1127, o fenômeno do aristotelismo estava ainda incipiente, e, todavia, já resulta presente no esquema de Hugo (ILICH, 2002, p. 21).

Ao lado das três formas de conhecimento, em que se reconhece o esquema aristotélico de teórico, prático e lógico, constrói-se uma quarta categoria filosófica, de conhecimento, InCID: R. Ci. Inf. e Doc., Ribeirão Preto, v. 1, n. 2, p. 60-76, jul./dez. 2010. 
constituída pela filosofia mecânica. A renovação do currículo é, sem dúvida, reveladora de necessidades e de aberturas. O que se verifica, todavia, é uma renovação de conteúdos, mas não de semântica da palavra filosofia, entendida como conhecimento: na época de Hugo de São Vítor, quem quisesse ser filósofo precisava "atravessar" a teologia. Enquanto reino do conhecimento humano possível, a filosofia inclui, necessariamente, também a categoria do conhecimento teológico. Nesse sentido, a disputa que se abre já com Abelardo destina-se a re-classificar os

conhecimentos, dentro de uma lógica de legitimação dentro dos espaços institucionais, as próprias universidades.

A definição que os profissionais laicos, os mestres das faculdades de artes, medicina e direito buscam é, de fato, de filósofos, colocando-se, nesse sentido, no mesmo nível de seus "colegas" teólogos. Essa disputa, no século XIII, foi jogada através do uso renovado de Aristóteles (DE LIBERA, 1999, p. 139-174).

\section{"Estudo de caso": Bolonha}

Deparamos com a busca de legitimação dessa categoria nova e, ao mesmo tempo, com a chegada, no ocidente, dos textos árabes. Procuramos, então, concentrar o foco em um dos centros principais de produção da iconografia universitária, Bolonha, e procurar as relações da instituição com o conhecimento aristotélico. Já no século XI mestres e estudantes se concentravam na cidade para ensinar e estudar direito, núcleo originário da universidade (VERGER, 2001, p. 89-114; GIORGI, 2004, p. 3-14). A essa faculdade agregaram-se, logo, as outras: as artes liberais, por exemplo, floresciam, especialmente a escola de retórica, redescoberta em função de sua funcionalidade, mas também a medicina, além das outras artes, a astronomia, a lógica, a matemática. A faculdade de teologia, porém, apareceu na universidade com muito atraso, somente em 1364. Até então, os estudos teológicos eram ministrados pelos franciscanos de São Domingos e pelo centro geral de estudos dos dominicanos, em São Nicolau.

Nesse sentido, a universidade torna-se lugar privilegiado de um ensino laico, particularmente conhecida pelo direito e pela medicina. Os primeiros docentes de medicina, em Bolonha, foram apreciados pela arte cirúrgica, uma medicina prática inspirada no modelo da escola de Salerno (TROCCHI, 1993, p. 9-13). Fundamentava-se em intervenções manuais e no 
uso de ervas, e revelava com clareza as influências árabes. Entre os primeiros mestres é atestada a presença de Rolando de Parma, portador dos conhecimentos oriundos da escola de Salerno.

A escola médica de Bolonha, todavia, não se limitou a inovar algumas práticas, pois potenciou aspectos teóricos da medicina, levando para outros centros, e principalmente para Paris, essa abordagem intelectual.

A grande mudança para centro de renovação intelectual, com o aparecimento de verdadeiros filósofos nas fileiras dos médicos e dos juristas, se torna possível com a chegada das traduções aristotélicas realizadas nos territórios do sul, na Sicília de Frederico II.

Com efeito, em 1224, por decreto imperial, funda-se a Universidade de Nápoles, com a finalidade de formar quadros de funcionários e juristas para o reino de Sicília (BEONIO BROCCHIERI, 2004, p. 99-104). Nesse sentido, a Universidade de Nápoles privilegiou a faculdade de direito, ladeada pelas outras Artes. Em Nápoles faltava unicamente a faculdade de medicina, pela proximidade geográfica com Salerno.

Coincidentemente, o imperador envia algumas cópias de manuscritos retirados de sua valiosa biblioteca de Palermo, em que se encontravam os saberes árabes, judeus e gregos que, pelo interesse do imperador, foram traduzidos em latim: na Sicília era possível estudar Aristóteles já sob o reino de Guilherme I.

As contingências políticas e de interesses criaram um caminho cultural de trocas entre Bolonha e os dois centros de estudos locados em território imperial, Nápoles e Salerno. De fato, a repercussão definitiva do Aristotelismo em Bolonha foi a introdução do estudo da filosofia natural no currículo da faculdade de medicina por obra de Tadeus Alderotti, já na metade do século XIII (GIORGI, 2004, p. 3).

Das conseqüências das condenações parisienses muito deve ter se falado na Itália, e em particular em Bolonha, onde o próprio Tadeus, bem conhecido por Dante Alighieri, remete à condenação em um comentário à Isagoge de Johannitius, composto logo depois 1277, em que o famoso médico não deixa de tornar explícitas suas simpatias pelos condenados (VERGER, 2001, 277-296). Uma das características dos aristotélicos radicais parisienses era a dedicação, de um lado, à filosofia natural e, do outro, à gramática especulativa, ou seja, um dos ramos das faculdades de artes.

InCID: R. Ci. Inf. e Doc., Ribeirão Preto, v. 1, n. 2, p. 60-76, jul./dez. 2010. 
A observação dos estudos sobre a cultura e a universidade de Bolonha revela uma explosão improvisa do aristotelismo radical ao longo das primeiras décadas do século XIV. Todavia, o trabalho de atribuição dos manuscritos inéditos aponta para uma anterioridade cronológica do averroismo em Bolonha, com várias presenças já no século XIII. Torna-se interessante, aqui, realçar as disputas que se revelam entre os círculos dos médicos e notários, todos oriundos da Faculdade de Artes, e os legistas, os juristas da faculdade de direito. No século XII a Faculdade de Direito se coloca como carro chefa da universidade, ladeada pela escola de dialética, mas a Escola de Medicina já está presente. Portanto, a filosofia natural e lógica também, estão presentes, enquanto de Salerno chegam as traduções grego-latinas de Aristóteles, destinadas a prosseguir para Montpellier e Paris (BEONIO BROCCHIERI, 2004, p. 84-98). É, portanto, razoável afirmar que os primeiros leitores de Aristóteles não foram os teólogos ou os juristas, mas sim os médicos e os filósofos naturais.

Paradigmática é a trajetória de Rolando de Cremona, que adquiriu sua cultura filosófica em Bolonha e, notadamente, seu conhecimento de Aristóteles (KNOWLES, 1984, p. 314 e 337). Na universidade foi chefe da escola de medicina antes de 1219, quando ingressa na ordem dominicana, se dedicando à teologia e alcançando, em 1229, o título de Magister Theologiae em Paris. Sua cultura científica aflora em suas obras, como na Suma de 1230, revelando, assim, a passagem do aristotelismo da categoria dos físicos à dos teólogos. Reforça também a hipótese da chegada das obras de Aristóteles em Bolonha não de Paris, mas do sul da Itália, uma carta, assinada pelo secretário imperial Pier delle Vigne, com a qual o imperador Frederico acompanha as traduções realizadas em sua corte: Bolonha aparenta ser o lugar ideal para receber e interpretar as novas propostas.

Protagonista dessa transferência foi, com toda probabilidade, Miguel Scoto, filósofo, mago, astrólogo e, acima de tudo, o responsável pela empreitada das traduções realizadas entre 1227 e 1235 de Aristóteles, Avicena e Averroés (ABBAGNANO, 2006, p. 211). Indícios disso são as indicações de sua presença na cidade universitária em 1220 e em 1231. O contexto cultural da época acarreta um grande interesse por parte dos intelectuais de Bolonha e, em particular, os médicos e filósofos naturais, pelas traduções. Logo depois da metade do século XIII a escola médica se constitui em Faculdade de Medicina e de Artes: os médicos passam a ensinar, 
estatutariamente, filosofia natural e lógica, identificando-se, assim, tanto como magistri naturalis scientiae quanto como magistri logicalis scientiae.

Realizam-se glosas de Aristóteles, de textos gregos e árabes de física e medicina, trabalhando nos moldes oferecidos pela tradição jurídica, da qual se assume também a técnica da quaestio disputata. A falta da Faculdade de Teologia deixa um amplo espaço intelectual a esse mundo de intelectuais laicos: há um farto elenco de magistri que transitam entre a Medicina e as Artes, que reforçam sua posição ao lado do outro setor intelectual, também laico, da jurisprudência, com as quais há disputas de reconhecimento, mas cujo efeito, nas primeiras décadas do século XIV, é o aparecimento de uma iconografia que revela as duas categorias como plenamente dignas de uma iconografia paritária dentro do espaço monumental.

\section{Disputas intelectuais}

Sobre as disputas entre Artistas e Juristas, vale a pena realçar um episódio significativo, pois revela que o campo de discussão envolve essa intelectualidade laica, que compete, em Bolonha, para sua legitimação uns sobre os outros, mas que, em um quadro mais amplo, se revela produtiva em redesenhar o intelectual laico. Trata-se da presença de algumas conhecidas personalidades do ateneu na Divina Commedia. A primeira referência à cidade e sua Universidade encontra-se no canto XV do Inferno, com a presença de Francesco D' Accursio, que ensinou direito em Bolonha, foi para Oxford em 1273 e voltou para Bolonha em 1280, onde permaneceu até falecer, em 1294. Assim como as outras personalidades presentes no círculo dos sodomitas, Brunetto Latini e Prisciano, a culpa do jurista consiste na ofensa blasfema à palavra de Deus, pois ele reivindicava para os juristas o ofício de "sacerdotes". Além da culpa "in orae" haveria aquela "in operae", pois teria contaminado o Corpus Iuris com um excesso de glosas, e ainda teria se dedicado à usura. (RAIMONDI, 1982, p. 39-63). Qualquer que seja a culpa do jurista, permanece a hostilidade de Dante em relação ao mundo das ciências jurídicas, que se inspira a uma visão de intelectual cujos traços se esboçam no Convívio: não "si dee chaimare vero filosofo colui che é amico di sapienza per utilitade, si come sono li legisti e li médici e quase tutti li religiosi, che non per sapere studiano, ma per acquistare moneta o dignitate". (ALIGHIERI, 1998). Dante se opõe com clareza à cultura mercenária dos professores, e desenha um ideal "nobre" de busca do conhecimento desinteressada.

InCID: R. Ci. Inf. e Doc., Ribeirão Preto, v. 1, n. 2, p. 60-76, jul./dez. 2010. 
A viagem do peregrino Dante é uma viagem de iluminação realizada pela leitura de um laico e por seu acesso ao conhecimento que é filosófico no sentido mais abrangente do termo. Virgílio é o primeiro guia, de natureza poética: a visão se dá quando o poeta está no meio do caminho de sua vida, considerado na época por volta de trinta e cinco anos. A poesia, como se observa na Vita Nova, é um despertar "espiritual” para um gênero de amor específico, o Amor Dei Intelectualis, no qual os sentidos são amplamente superados pelo amor que uma mente cultivada encontra em sua aproximação com Deus (CORTI, 2003). Na Commedia, o Inferno não é somente um percurso de punição, ele se realiza instigado pelas leituras poéticas. A poesia é capaz de despertar a alma humana para o senso do pecado, encontrando uma arma privilegiada na alegoria dos poetas, que permite ao mecanismo de narração dos fatos individuais uma interpretação cristológica, um acesso a uma "verdade" superior que, porém, ainda não desvela os mistérios de Deus. Os espaços das paixões desenfreadas e da humanidade alheia ao espírito divino e condenada podem ser explorada através da poesia, fio de Ariadne encarnado em Virgílio, que permite atravessar as paixões sem pecar. Ao lado de personagens do tempo do poeta, encontramos uma galeria de outros que povoam as páginas da literatura pagã.

O primeiro movimento do homem é conhecer o pecado. A primeira leitura no percurso de salvação é aquela que ilumina os olhos através da revelação do sofrimento e a escuridão a que os pecados gerados pelas paixões levam, a poesia.

O segundo momento da viagem, o Purgatório, é o encontro do poeta com si mesmo, o lugar onde, a certa altura, se depara com os soberbos que carregam pedras tão pesadas que os mantêm dobrados. Purgatório é o espaço onde Dante discute a função da poesia como resgate do pecado, após que a mesma permitiu conhecer os sofrimentos. Há, no purgatório, uma interessante galeria de representantes da poesia cristã.

O Paraíso, terceiro canto da obra, não é mais de alçada do poeta e não conta mais com as possibilidades limitadas do espaço poético. É o espaço do conhecimento teológico ipso facto e da expressão manifesta da luminosidade de Deus que o poeta só consegue encarar depois de ter cumprido o percurso de conhecimento com suas leituras. De fato, a lista de autores que compõem a rosa dos sábios é integrada na própria estrutura do poema dantesco. Para chegar a sentar entre os doutores, Dante incorporou essas leituras. Elas permitem que o poeta encare a luz da sabedoria divina, a Sapientia, atributo divino no centro da reflexão de Hugo:

InCID: R. Ci. Inf. e Doc., Ribeirão Preto, v. 1, n. 2, p. 60-76, jul./dez. 2010. 
... Bonaventura da Bagnoregio [...] / Illuminato ed Agostin son quici [...] / Ugo da San Vittore [...], e Pietro Mangiadore e Pietro Ispano [...] Natàn profeta e 'l metropolitano Crisostomo e Anselmo e quel Donato [...] / Rabano é qui [...] il calavrese abate Gioacchino [...] / São Tomás (ALIGHIERI, 2005).

À iconografia dos mestres laicos, expressão visual de um espaço e de uma legitimidade intelectual conquistada através de duras disputas universitárias, corresponde a aspiração literária laica de Dante, que aponta para a possibilidade de sentar no céu dos sábios, dos filósofos, participando, com pleno direito, do conhecimento mais alto, que leva à salvação. Nesse sentido, em um contexto que em nada ameaça a estabilidade das antigas estruturas do universo, a legitimidade é obtida através da busca de integração nos degraus hierárquicos mais altos da instituição universitária, e não através de um antagonismo, impossível no quadro medieval de um universo cristão. Todavia, o movimento renovador iniciado pelos pensadores laicos, sua busca de um espaço intelectual legítimo externo às ordens religiosas abre uma trilha de reflexões necessárias para uma derrocada da cronologia medieval, elegendo a universidade como eixo de grande importância na disputa entre tradição e modernização.

\section{Referencias bibliográficas}

ABBAGNANO, Nicola. Storia della filosofia: il pensiero medievale e rinascimentale; dal misticismo a Bacone. Novara: Istituto Geográfico de Agostini, 2006.

ALIGHIERI, Dante. Convivio. [s.l.]: E-text, 1998. 98 p. Disponível em: $<$ www.liberliber.it/biblioteca/a/alighieri/convivio_edizione_vasoli_de_robertis/pdf/conviv_p.pdf >. Acesso em: 10 nov. 2010.

La divina commedia. [s.1.]: E-text, 2005. 422 p. Disponível em:

$<$ www.liberliber.it/biblioteca/a/alighieri/la_divina_commedia/pdf/la_div_p.pdf $>$. Acesso em: 10 dez. 2010

BASCHET, Jérôme. I mondi del medioevo: i luoghi dell'aldilà. In: CASTELNUOVO, Enrico e SERGI, Giuseppe. Arti e storia nel medioevo: tempi, spazi, istituzioni. Torino: Einaudi, 2002.

BEONIO BROCCHIERI, Mariateresa F. Federico II: ragione e fortuna. Bari: Laterza, 2004.

BOLZONI, Lina. La rete delle immagini: predicazione in volgare dalle origini a Bernardino da Siena. Torino: Einaudi, 2002.

CARNAZZI, Giulio; FEDRIGA, Riccardo. Il mondo in un libro. Milano: Sylvestre Bonnard, 2002. 
CORTI, Maria. Studi su Cavalcanti e Dante. Torino: Einaudi, 2003.

DE LIBERA, Alain. Pensar na Idade Média. São Paulo: 34, 1999.

GIORGI, Piero P. Mondino de' Liuzzi e la nascita dell' anatomia moderna. In: CALZOLARI, Pier Ugo (Org.). Rappresentare il corpo: arte e anatomia da Leonardo all' Illuminismo:

Catalogo da exposição. Bologna: Bononia University Press, 2004.

GOMBRICH. Aby Warburg: una biografia intellettuale. Milano: Feltrinelli, 2003.

HUGO DE SÃO VITOR. Didascalicon: da arte de ler. Petrópolis: Vozes, 2001.

ILICH, Ivan. En el viñedo del texto: etología da la lectura: un comentario al "Didascalicon" de Hugo de San Victor. México: Fondo de Cultura Economica, 2002.

KNOWLES, David. L’evoluzione del pensiero medievale. Bologna: Il Mulino, 1984.

LE GOFF, Jacques. Gli intellettuali nel medioevo. Milano: Mondadori, 1993.

PANOFSKY, Erwin. Architettura gótica e filosofia scolastica. Napoli: Liguori, 1986.

Studi di iconologia: i temi umanistici nell'arte del Rinascimento. Torino: Einaudi, 1975.

RAIMONDI, Ezio. Metafora e storia: studi su Dante e Petrarca. Torino: Einaudi, 1982.

SAXL, Fritz. La storia della immagini. Bari: Laterza, 2005.

SCHMITT, Jean-Claude. Les images classificatrices. Bibliothèque de l'École dês chartes, t. $147,1989$.

SETTIS, Salvatore. Warburg continuatus: descrição de uma biblioteca. In: BARATIN, Marc; JACOB, Christian (Org.). O poder das bibliotecas: a memória dos livros no ocidente. Rio de Janeiro: UFRJ, 2000.

TROCCHI, Cecília G. (Org.). La regola sanitária salernitana. Milano: Newton, 1993.

VERGER, Jacques. Cultura, ensino e sociedade no ocidente nos séculos XII e XIII. Bauru: EDUSC, 2001.

Homens e saber na Idade Média. Bauru: EDUSC, 1999. 